\title{
TOEPLITZ OPERATORS AND WEIGHTED NORM INEQUALITIES ON THE BIDISC
}

\author{
TAKAHIKO NAKAZI
}

Abstract. Let $H^{p}$ be the Hardy space on the bidisc and $1<p<\infty$. For a function $\phi$ in $L^{\infty}$, we study the norm of the Hankel operator $H_{\phi}$ on $H^{p}$ and the invertibility of the Toeplitz operator $T_{\phi}$ on $H^{p}$. The latter is strongly related to weighted norm inequalities on the bidisc.

Mathematics subject classification (2000): 47B35, 42B20.

Key words and phrases: Toeplitz operator, weighted norm inequality, several variables, invertibility, Hankel operator.

\section{REFERENCES}

[1] A. BötTCher AND B. Silbermann, Analysis of Toeplitz operators, Springer-Verlag..

[2] M. COTLAR AND C. SADOSKY, Two-parameter lifting theorems and double Hilbert transforms in commutative and non-commutative settings, J. Math. Anal. Appl. 150 (1990), 439-480.

[3] M. Cotlar And C. SADOSKY, The Helson-Szegö theorem in $L^{p}$ of the bidinensional torus, Contemp. Math. 107 (1990), 19-37.

[4] M. Cotlar And C. SAdosky, Nehari and Nevanlinna-Pick Problems and holomorphic extensions in the polydisk in terms of restricted BMO, J. Funct. Analy. 124 (1994), 205-210.

[5] J. GARNETT, Bounded analytic functions, Academic Press (1981).

[6] R. Hunt, B. Muckenhoupt AND R. L. WheEden, Weighted norm inequalities for the conjugate function and the Hilbert transform, Trans. Amer. Math. Soc. 176 (1973), 227-252.

[7] T. NAKAZI, Extended weak ${ }^{-*}$ Dirichlet algebras, Pacific J. Math. 81 (1979), 493-513.

[8] T. NAKAZI, Norms of Hankel operators on a bidisc, Proc. Amer. Math. Soc. 108 (1990), 715-719.

[9] T. NAKAZI, Errata to "Norms of Hankel operators on a bidisc", Proc. Amer. Math. Soc. 115 (1992), 873.

[10] T. NAKAZI, Toeplitz operators and weighted norm inequalities, Acta Sci. Math 58 (1993), 443-452.

[11] T. NAKAZI, An outer function and several important functions in two variables, Arch. Math. 66 (1996), 490-498.

[12] Z. NeHARI, On bounded bilinear forms, Ann. of Math. 65 (1957), 153-162.

[13] R. RochBeRG, Toeplitz operators on weighted $H^{p}$ spaces, Indiana Univ. Math. J. 26 (1977), 291-298.

[14] W. Rudin, Function Theory In Polydiscs, New York (1969). 